\title{
Biodegradation of 1,1,1-Trichloro-2,2-bis (4-chlorophenyl) ethane (DDT) by Mixed Cultures of White-Rot Fungus Ganoderma lingzhi and Bacterium Pseudomonas aeruginosa
}

\author{
Erly Grizca Boelan ${ }^{1}$, Adi Setyo Purnomo ${ }^{2 *}$ \\ ${ }^{1}$ Department of Chemistry Education, Universitas Katolik Widya Mandira, Kupang, Indonesia \\ ${ }^{2}$ Department of Chemistry, Institut Teknologi Sepuluh Nopember, Kampus ITS Sukolilo, Surabaya, Indonesia
}

\section{ARTICLE INFO}

Article history:

Received July 19, 2018

Received in revised form September 18, 2018

Accepted February 11, 2019

KEYWORDS:

Biodegradation,

DDT,

Mixed Cultures,

Ganoderma lingzhi,

Pseudomonas aeruginosa

\begin{abstract}
This study investigated the biodegradation of 1,1,1-trichloro-2,2-bis (4-chlorophenyl) ethane (DDT) by mixed cultures of white-rot fungus Ganoderma lingzhi and bacterium Pseudomonas aeruginosa. Bacterium P. aeruginosa culture with various volumes $1,3,5,7$, and $10 \mathrm{ml}\left(1 \mathrm{ml} \approx 1.53 \times 10^{9}\right.$ bacteria cells $/ \mathrm{ml}$ cultures) was added into $10 \mathrm{ml} G$. lingzhi culture for degrading DDT. After 7 d incubation, DDT was degraded about $100 \%$ with addition of 5,7 , and $10 \mathrm{ml}$ of $P$. aeruginosa culture into $G$. lingzhi. Two metabolites; 1,1-dichloro-2,2-bis (4-chlorophenyl) ethane (DDD) and 1-chloro,2-2-bis (4-chlorophenyl) ethylene (DDMU) were detected from mixed cultures of $G$. lingzhi and P. aeruginosa as metabolic products of DDT. This research indicated that mixed cultures of whiterot fungus $G$. lingzhi and bacterium $P$. aeruginosa could be used to degrade DDT.
\end{abstract}

\section{Introduction}

The organochlorine pesticide 1,1,1-trichloro-2,2-bis (4-chlorophenyl) ethane (DDT) was one of the first synthetic pesticides widely used in the world since the 1940s. The use of DDT was increased substantially since World War II for control agricultural pest and control insect borne diseases such as thypus and malaria (Curtis and Lines 2000; Turusov et al. 2002; Booij et al. 2016). Since the late 1970s, DDT has been banned for agricultural use in most countries because of its high toxicity, extremely hydrophobic and persistency lead to biological magnification and accumulation, and within the food chain bring on high degree of contamination (Curtis and Lines 2000; Turusov et al. 2002). Though the use of DDT has been banned, in several countries DDT still being used for essential public health purposes such as eradicate malaria (Curtis and Lines 2000).

In recent years, research on DDT has become an environmental priority because DDT and its metabolites have high resistance to degradation and relatively long half-life about 15 years up to 36 years in soil (Zhao et al. 2010). DDT has covered some health problems such as increase tumor production, DNA damage in

\footnotetext{
* Corresponding Author

E-mail Address: adi_setyo@chem.its.ac.id
}

blood cells and disruption of synthesis and metabolism of endogenous hormones, interruption the functions of respiratory system, and attack on central nervous system. Therefore, DDT is still a serious environmental problem and efficient remediation method is required.

Many researchers have reported that microorganism fungi and bacteria have ability to degrade DDT and transform to another metabolite (Aislabie et al. 1997; Foght et al. 2001; Rubilar et al. 2013). Recently, biodegradation of DDT was performed using mixed cultures by microorganisms. Purnomo et al. 2017 reported that culture of white-rot fungus Pleurotus ostreatus has synergistic effect with biosurfactantproducing bacteria Pseudomonas aeruginosa and Bacillus subtilis. DDT was eliminated by mixed cultures of $P$. ostreatus- $3 \mathrm{ml}$ of $P$. aeruginosa $\left(1 \mathrm{ml} \approx 1.25 \times 10^{9}\right.$ bacteria cells/ml cultures) and $P$. ostreatus $-5 \mathrm{ml}$ of $B$. subtilis ( $1 \mathrm{ml} \approx 1.25 \times 10^{9}$ bacteria cells/ml cultures) about $85.74 \%$ and $43 \%$ respectively in PDB medium during 7 $\mathrm{d}$ incubation. In another study, DDT was degraded by mixed cultures brown-rot fungus Fomitopsis pinicola $\neg$ and $10 \mathrm{ml}$ of $P$. aeruginosa $\left(1 \mathrm{ml} \approx 6.7 \times 10^{8}\right.$ bacteria cell $/ \mathrm{ml}$ cultures) and $F$. pinicola- $10 \mathrm{ml}$ of $B$. subtilis ( 1 $\mathrm{ml} \approx 1.53 \times 10^{9}$ bacteria cell $/ \mathrm{ml}$ cultures) approximately $68 \%$ and $86 \%$ during $7 \mathrm{~d}$ in PDB medium (Sariwati et al. 2017; Sariwati and Purnomo 2018).

Ganoderma lingzhi (before 2012 known as Ganoderma lucidum) is one of the most important and widely 
distributed white-rot fungus in the world that has the ability to degrade variety wood (D'Souza et al. 1999). Its capacity to degrade DDT is not well known. Recent studies, (Da Silva et al. 2010a; Da Silva et al. 2010b) reported G. lingzhi can remove herbicide bentazon in liquid and solid states condition approximately $55 \%$ and $90 \%$ after $10 \mathrm{~d}$ cultivation. In another report, G. lingzhi can enhance degradation processes of trichloroethylene, polycyclic aromatic and hydrocarbons (PAHs) and pentachlorophenol (Jeon et al. 2008; Punnapayak et al. 2009; Ting et al. 2011). This information lets us pay attention to G. lingzhi in its capability to degrade DDT.

$P$. aeruginosa is found in water and soil and can grow in areas that contain oil and other fuel oils. Thus, this bacterium can be used to degrade hydrocarbon pollutants in the aquatic environment as well as in the soil. $P$. aeruginosa can produce biosurfactant rhamnolipid which can increase dispersion or surface area for microbial attachment (Miller and Zhang 1994; Al-tahhan et al. 2000; Moussa et al. 2014). Because DDT is a hydrophobic compound, then the addition of biosurfactant can increase the solubility of DDT thereby optimizing the degradation process. The aims of this research were investigated the ability of mixed cultures $G$. lingzhi and $P$. aeruginosa to degrade DDT.

\section{Materials and Methods}

\subsection{Chemicals}

DDT and pyrene were purchased from Tokyo Chemical Industry Co (Tokyo, Japan). Acetone and $n$-hexane were purchased from Anhui Fulltime specialized solvent and reagent Co., Ltd (Anhui China). Dimethyl sulfoxide (DMSO), methanol and sodium sulfate anhydrous were purchased from Merck Millipore (Darmstadt, Germany).

\subsection{Microorganisms Culture Conditions}

Stock cultures of G. lingzhi BMC 9057 were grown on Potato Dextrose Agar (PDA, Merck Darmstadt, Germany) plates that had been incubated statically at $30^{\circ} \mathrm{C}$. G. lingzhi mycelia $(1 \mathrm{~cm}$ diameter) was inoculated into $10 \mathrm{ml}$ of Potato Dextrose Broth (PDB, Merck Darmstadt, Germany) medium and then preincubated statically for $7 \mathrm{~d}$ at $30^{\circ} \mathrm{C}$.

Bacterial cultures of $P$. aeruginosa NBRC 3080 (NITE Biological Resource Center, NBRC; Chiba, Japan) were grown on Nutrient Agar (NA; Merck Darmstadt, Germany) medium which was incubated at $37^{\circ} \mathrm{C}$. The colony was inoculated into $60 \mathrm{ml}$ of Nutrient Broth (NB, Merck, Darmstadt, Germany) medium and preincubated for $21 \mathrm{~h}$ at $37^{\circ} \mathrm{C}$ with shaker condition 180 rpm (Purnomo et al. 2008; Purnomo et al. 2017; Sariwati et al. 2017; Sariwati and Purnomo 2018).

\subsection{Biodegradation of DDT by G. lingzhi}

Cultures G. lingzhi after pre-incubation for $7 \mathrm{~d}, 10$ $\mathrm{ml}$ of PDB medium and $50 \mu \mathrm{l}$ of $5 \mathrm{mM}$ DDT in DMSO as a substrate were added to each inoculated flask (final concentration, $0.25 \mu \mathrm{mol}$ ). The headspace of each flask was flushed with oxygen and then sealed with a glass stopper and sealing tape to prevent the volatilization of the substrate. The cultures were incubated statically for $7 \mathrm{~d}$ at $37^{\circ} \mathrm{C}$. As a control, the cultures were killed by autoclaving $\left(121^{\circ} \mathrm{C}, 20 \mathrm{~min}\right)$ after pre-incubation (Purnomo et al. 2017; Sariwati et al. 2017; Sariwati and Purnomo 2018).

\subsection{Biodegradation of DDT by $P$. aeruginosa}

Culture bacterium $P$. aeruginosa (after preincubation for $21 \mathrm{~h}$ ) was inoculated to PDB medium (final volume $20 \mathrm{ml}$ ) with a various volume 1, 3, 5, 7, and $10 \mathrm{ml}\left(1 \mathrm{ml} \approx 1.53 \times 10^{9}\right.$ bacteria cell $/ \mathrm{ml}$ cultures $)$. As substrate, $50 \mu$ l of $5 \mathrm{mM}$ DDT in DMSO was added to each inoculated flask. The headspace of each flask was flushed with oxygen and then sealed with a glass stopper. The sealing tape is used to prevent the volatilization substrate. The cultures were incubated statically for $7 \mathrm{~d}$ at $30^{\circ} \mathrm{C}$. As the control, the cultures were killed by autoclave $\left(121^{\circ} \mathrm{C}, 20 \mathrm{~min}\right)$ (Purnomo et al. 2017; Sariwati and Purnomo 2018).

\subsection{Biodegradation of DDT by Mixed Cultures of $\mathbf{G}$. lingzhi and $P$. aeruginosa}

$1,3,5,7$, and $10 \mathrm{ml}$ of pre-incubated $P$. aeruginosa cultures were inoculated separately into $10 \mathrm{ml}$ of G. lingzhi culture with final volume $20 \mathrm{ml}$. DDT (50 $\mu \mathrm{l}$ of $5 \mathrm{mM}$ ) in DMSO was added to each flask. The headspace of each flask was flushed with oxygen and sealed with glass stopper and then sealing tape to prevent the volatilization of substrate. The cultures were incubated statically for $7 \mathrm{~d}$ at $30^{\circ} \mathrm{C}$. As a control, after incubation the cultures were killed by autoclave $\left(120^{\circ} \mathrm{C}, 20 \mathrm{~min}\right)$ (Purnomo et al. 2017; Sariwati et al. 2017; Sariwati and Purnomo 2018).

\subsection{DDT Recovery}

After incubation process, $50 \mu \mathrm{l}$ of pyrene $5 \mathrm{mM}$ in DMSO (final concentration $0.25 \mu \mathrm{mol}$ ) was added into the flask as internal standard, followed washed with $20 \mathrm{ml}$ of methanol and $5 \mathrm{ml}$ of acetone. The residual biomass was removed by centrifugation at $3,000 \mathrm{rpm}$ for $10 \mathrm{~min}$. The supernatant was filtrated using Whatman Filter Paper 41 (GE Healthcare Life Science, UK) and the filtrate was evaporated at $64^{\circ} \mathrm{C}$ and extracted with $200 \mathrm{ml} n$-hexane. The organic fraction was collected and dried over anhydrous sodium sulfate. The extracts were evaporated at $68^{\circ} \mathrm{C}$ and concentrated to dryness under reduced pressure. 
The concentrate was diluted with methanol and then analyzed by High-Performance Liquid Chromatography (HPLC) to quantify the amount of substrate. HPLC was conduced with a Shimadzu LC20AT pump and a Shimadzu SPD-M20A diode array detector fitted with an Inertsil ODS-4 column (250 $\mathrm{mm}$ ) with an inner diameter of $4.6 \mathrm{~mm}$ (GL Science, Tokyo). The samples were eluted with $82 \%$ methanol in a $0.1 \%$ trifluoroacetic acid aqueous solution at a flow rate of $1 \mathrm{ml} / \mathrm{min}$ (Sariwati and Purnomo 2018).

To identify the metabolites of DDT, samples were further diluted with $n$-hexane and then analyzed by GC-MS. The GC-MS was performed on a 7890A GC system (Agilent Technologies, USA) linked to a 5975C VL MSD Triple-Axis Detector (Agilent Technologies, USA) with a 30-m Agilent 19091S-433 column (Agilent Technologies, USA). The oven temperature was programmed at $100^{\circ} \mathrm{C}$ for $3 \mathrm{~min}$, followed by a linear and increased to $200^{\circ} \mathrm{C}$ at $20^{\circ} \mathrm{C} \mathrm{min}{ }^{-1}$ and

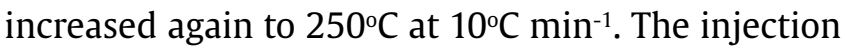
was splintedless approximately $1 \mu \mathrm{l}$.

\section{Results}

White-rot fungus $G$. lingzhi and bacterium $P$. aeruginosa have been investigated as a new mixed cultures for biodegradation of DDT. In this research, environmental parameter was manipulated using medium that allows growth and degradation process. G. lingzhi grew well at NB and PDB medium at $30^{\circ} \mathrm{C}$ but at high temperatures, its growth was bad. While, $P$. aeruginosa grew well at NA and PDB medium at $30^{\circ} \mathrm{C}$.

During $7 \mathrm{~d}$ incubation period, DDT was degraded about $52.52 \%$ by G. lingzhi. Degradation DDT by bacterium $P$. aeruginosa at $1,3,5,7$, and $10 \mathrm{ml}$ volumes of bacteria ( $1 \mathrm{ml} \approx 1.52 \times 10^{9}$ bacteria cell $/ \mathrm{ml}$ culture) during $7 \mathrm{~d}$ incubation is shown in Table 1 . Degradation rate increased from 1 to $7 \mathrm{ml}$ but decrease at $10 \mathrm{ml}$. Bacterial culture of $P$. aeruginosa at $10 \mathrm{ml}$ degraded DDT about $65.98 \%$, which was lower compered to 7 $\mathrm{ml}$ that was degrade DDT about $90.20 \%$. This result indicated that $G$. lingzhi and P. aeruginosa have a greater potential to degrade DDT.

In the present study the ability of mixed cultures of white-rot fungus $G$. lingzhi and bacterium P. aeruginosa to degrade DDT was investigated. The analysis result of degradation of DDT by mixed cultures of G. lingzhi and $P$. aeruginosa are shown in Table 1 and Figure 1.

Table 1. Degradation of DDT by G. lingzhi and P. aeruginosa as well as by mixed cultures

\begin{tabular}{clc}
\hline Bacterial & \multicolumn{2}{c}{$\%$ Degradation of DDT } \\
\cline { 2 - 3 } concentration $(\mathrm{ml})$ & P. aeruginosa & Mixed cultures \\
\hline G. lingzhi (only) & $52.52 \pm 0.68$ & \\
1 & $75.17 \pm 2.06$ & $59.11 \pm 0.81$ \\
3 & $82.13 \pm 2.34$ & $91.34 \pm 0.73$ \\
5 & $86.15 \pm 0.51$ & $100 \pm 0.00$ \\
7 & $90.20 \pm 0.16$ & $100 \pm 0.00$ \\
10 & $65.98 \pm 0.87$ & $100 \pm 0.00$ \\
\hline
\end{tabular}

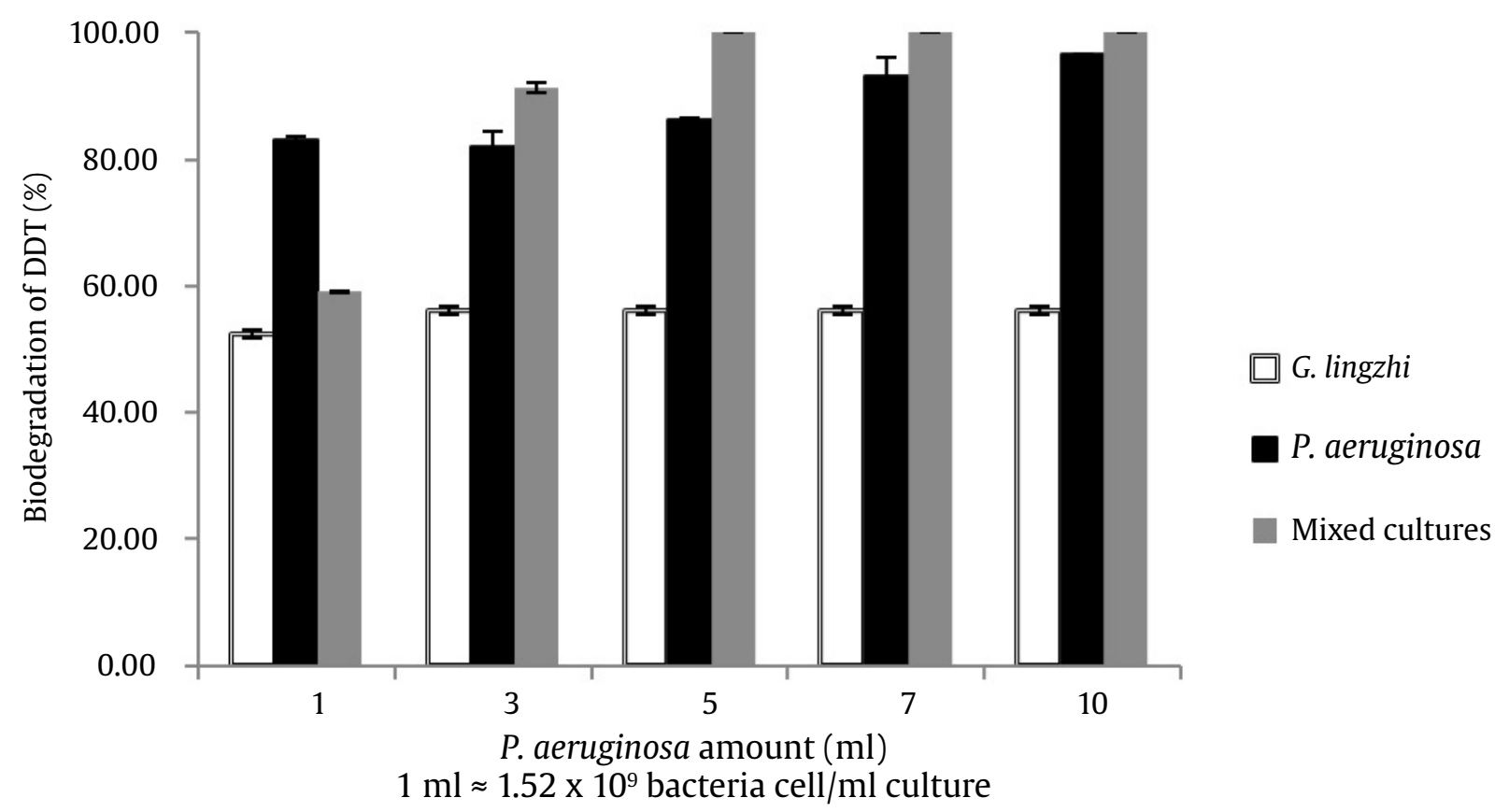

Figure 1. Biodegradation of DDT by mixed cultures of G. lingzhi and P. aeruginosa 
The addition of bacterium $P$. aeruginosa into cultures of G. lingzhi gave significant effect on degradation of DDT, where the degradation rate increases $100 \%$ in addition of 5,7 , and $10 \mathrm{ml}$ cultures bacteria after $7 \mathrm{~d}$ incubation. This result indicates that the mixed cultures of $G$. lingzhi and $P$. aeruginosa can increase the DDT degradation rate.

Based on GC-MS analysis, DDD, and DDE were detected as metabolites of DDT degradation by G. lingzhi while DDD and DDMU were detected as metabolites from degradation of DDT by $P$. aeruginosa (data not shown). Figure 2 showed DDE and DDMU, which are the metabolites obtained from degradation of DDT by mixed cultures of G. lingzhi and P. aeruginosa after extraction and analysis by GC-MS with comparing their retention time and mass spectra with those of available standard compounds. The peak at retention time of $11.3 \mathrm{~min}$ had $\mathrm{m} / \mathrm{z} 212$, which identified as DDMU. The peak at retention time of $13.4 \mathrm{~min}$ had $\mathrm{m} / \mathrm{z} 235$, which identified as DDD. The internal standard peaks appeared in control and treatment samples at $\mathrm{m} / \mathrm{z} 202$, which identified as pyrene. In this result, DDT was not detected, its equivalent to the degradation result. DDT possibly transformed into DDD and DDMU.

\section{Discussion}

Biodegradation is a good alternative to clean-up contaminants using biological activity. In this method, contaminant can be metabolized by microorganisms and can beeffective only whereenvironmental condition permit microbial growth and activity. Punnapayak et al. 2009 reported that G. lucidum Chaaim-001 BCU grew well at $30^{\circ} \mathrm{C}$ but at temperatures above $30^{\circ} \mathrm{C}$ the growth was poor. While, $P$. aeruginosa that can be grown easily in a wide variety of condition and temperatures.

A successful biodegradation technique requires an efficient microorganism that can degrade the largest pollutants to minimum level. Fungi and bacteria are very good degrader of pollutants. They use the contaminant as the source of carbon and energy for growth and metabolism. G. lingzhi is a white-rot fungus that has potential ability as traditional medicine. Beside that, G. lingzhi could degrade the major components of plants cell wall including lignin, cellulose and hemicelluloses (Liu et al. 2012). In general, the ability of G. lingzhi to degrade DDT is related to the ability to degrade cellulose and lignin. According to Liu et al. 2012, G. lingzhi has many genes might be involved in degradation process including 216 putative glycoside hydrolases, 56 putative glycosyl transferase, 16 laccase, 7 peroxidase, and 9 glyoxal oxidase genes. Moreover, G. lingzhi showed rich P450 family which enzymes catalyze of variety reaction.

Ligninolytic enzymes such as Mangan Peroxidase (MnP), Lignin Peroxidase (LiP), and Laccase have played an important role in degradation or transformation of several xenobiotic compounds. Some reports mentioned that laccase is one of the most applied in biodegradation because its board substrate specificity

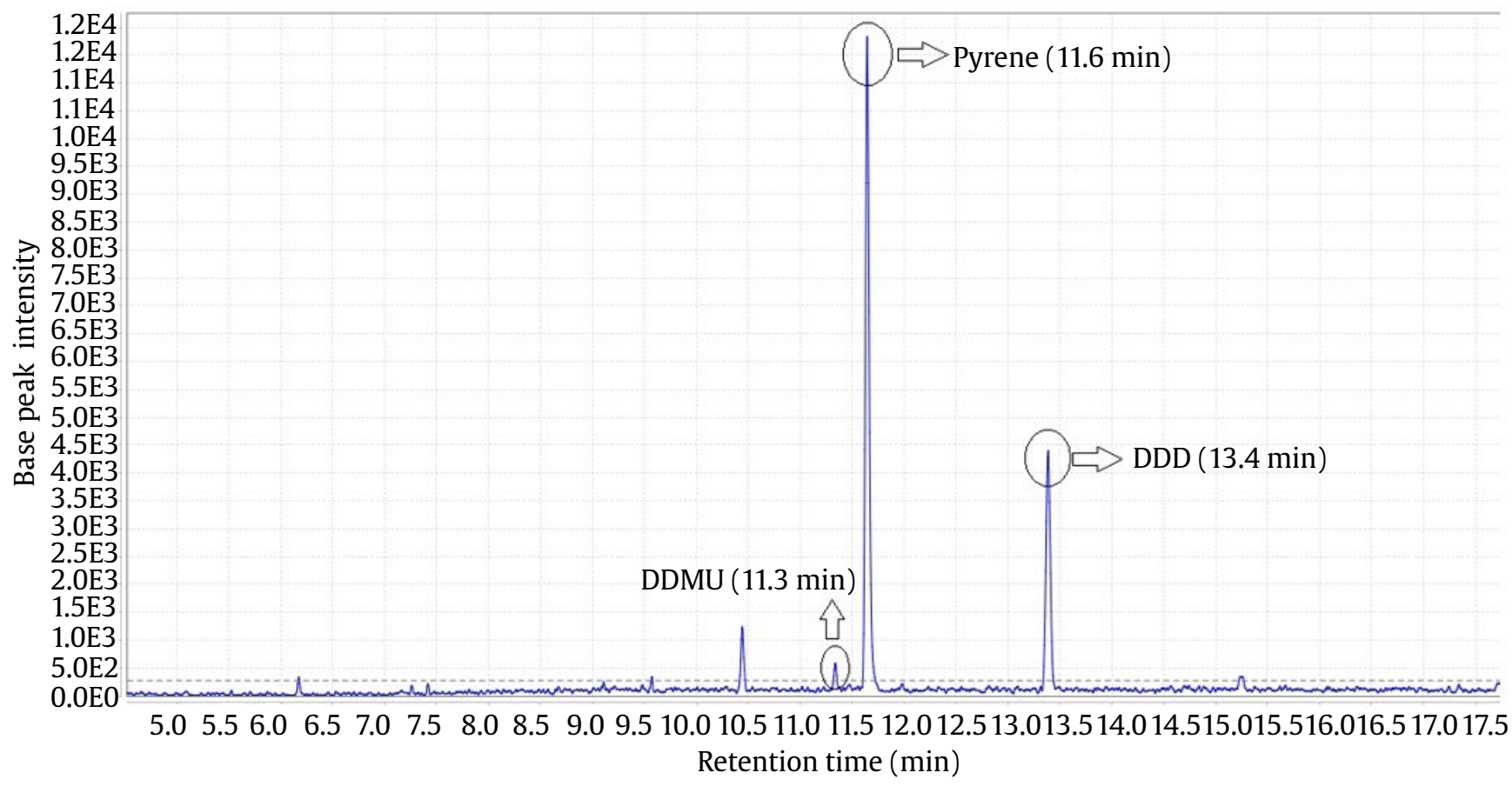

Figure 2. Chromatogram of DDT biodegradation by mixed cultures of G. lingzhi and $5 \mathrm{ml}$ of P. aeruginosa in $7 \mathrm{~d}$ incubation 
(Canas and Camarero 2010). Da Silva et al. 2010 reported herbicide bentazon was degraded by G. lingzhi approximately $90 \%$ and $55 \%$ in solid state and liquid cultures respectively.

Degradation of DDT by $P$. aeruginosa at various volumes is shown in Table 1 . After $7 \mathrm{~d}$ incubation period, DDT was degraded approximately $75 \%, 82 \%$, $86 \%, 90 \%$, and $66 \%$ at $1,3,5,7$, and $10 \mathrm{ml}$ of bacteria in PDB medium respectively. P. aeruginosa is bacterium that has potential for degradation of DDT. The highest degradation rate was recorded at $7 \mathrm{ml}$ volume of bacteria approximately $90 \%$. While at $10 \mathrm{ml}$ degradation rate was decrease approximately $66 \%$. It indicated, in excess concentration of bacterium $P$. aeruginosa can decrease degradation of DDT. In stationary phase, bacteria can produce some secondary metabolites that may be toxic for other in order to survive.

In previous report, $P$. aeruginosa DT-Ct1 can degrade $5 \mathrm{ppm}$ of DDT completely in 4 days incubation (Bidlan 2003). Furthermore, Kamanayalli and Ninnerkar 2004 reported Pseudomonas species has the ability to transform DDT to 4-chlorobenzoic acid.

Biodegradation process will work fine depends on the nature of organisms, the enzyme involved, its concentration and availability in its survival microorganism. According to Das 2014, microorganisms can grow by utilizing pesticides as an energy source at the biodegradation of pesticides.

Study about mixed cultures of microorganisms to degrade xenobiotic compounds was reported. Endosulfan was eliminated efficiently by co-cultures of bacteria were collected from mixed and pure cultures in aerobic and facultative aerobic condition (Awasthi et al. 1997; Kumar and Philip 2006). Other studies reported mixed cultures fungi and bacteria have an ability to degrade xenobiotic compound. Hai et al. 2012 reported that effect of combining fungus and bacteria cultures can improve the removal rates of pesticides aldicarb, antrazine and alachlor approximately $47.98 \%$ and $62 \%$ respectively. Purnomo et al. 2017 reported mixed cultures of white-rot fungus P. ostreatus $-5 \mathrm{ml}$ of $B$. subtilis and P. ostreatus $-3 \mathrm{ml}$ of $P$. aeruginosa can degrade DDT about $43.00 \%$ and $85.74 \%$ respectively during $7 \mathrm{~d}$ incubation. In another research, Sariwati et al. 2017 reported that co-cultures of brown-rot fungus $F$. pinicola and $10 \mathrm{ml}$ of $B$. subtilis removed DDT about $85.87 \%$ during $7 \mathrm{~d}$ incubation.

In comparison with several previous studies, we reported that degradation of DDT by mixed cultures of $G$. lingzhi and $P$. aeruginosa is more effective than mixed cultures $P$. ostreatus $-5 \mathrm{ml}$ of P. aeruginosa and also F. pinicola- $10 \mathrm{ml}$ of P. aeruginosa were approximately $69 \%$ and $67 \%$ respectively (Purnomo et al. 2017; Sariwati and Purnomo 2018). This might be caused by the ability of $G$. lingzhi to produce many genes that can involve in degradation process and also the ability $P$. aeruginosa to produce a rhamnolipid biosurfactant, which can improve the solubility of DDT.

G. lingzhi metabolized DDT to DDD and DDE, while $P$. aeruginosa produced DDD and DDMU. Based on identification of metabolic products by GC-MS, a DDT transformation pathway is proposed (Figure 3.). This result indicated bacteria have an important role in DDT transformation. The mechanisms of microbial attack have already been described. Most reports indicate that DDT is reductive dechlorinated to DDD involving substitution of an aliphatic chlorine for a hydrogen atom. DDMU was also produced from reductive dechlorination of DDD.

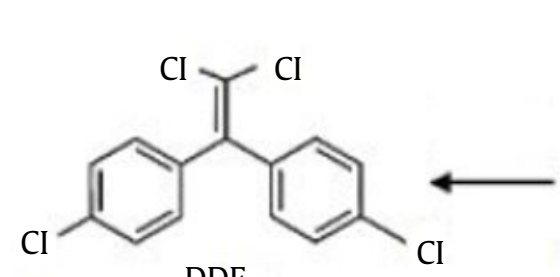

DDE

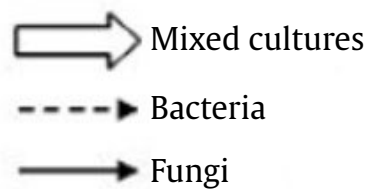<smiles></smiles>

DDT

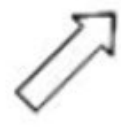

DDMU

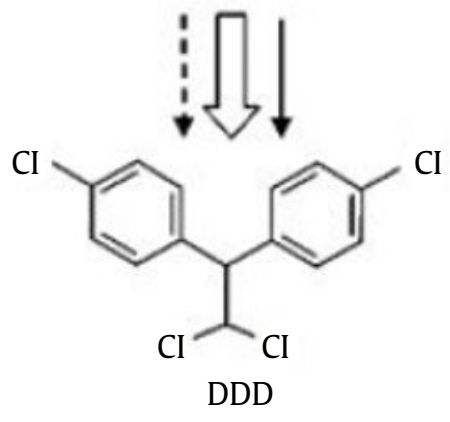

Figure 3. Proposed DDT degradation pathways by particular G. lingzhi and P. aeruginosa as well as by mixed cultures 


\section{Acknowledgements}

This work was supported by a grant from the Research Project for "Penelitian Unggulan Perguruan Tinggi" (PUPT) 2016, from Directorate General of HigherEducation, Ministry of research, Technology and Higher Education, Indonesia.

\section{References}

Aislabie JM et al. 1997. Microbial degradation of DDT and its residues-A review. New Zealand J Agr Research 40:269-282.

Al-tahhan RA et al. 2000. Rhamnolipid-induced removal of lipopolysaccharide from Pseudomonas aeruginosa: effect on cell surface properties and interaction with hydrophobic substrate. Appl Environ Microbiol 66:3262-3268.

Awasthi $\mathrm{N}$ et al. 1997. Biodegradation of endosulfan by a bacterial coculture. Bull Environ Contam Toxicol 59:928-934.

Bidlan R. 2003. Studies in DDT biodegradation by bacterial strains [Thesis]. Karnataka, India: University of Mysore.

Booij P et al. 2016. Current implications of past DDT indoor spraying in Oman. Sci Total Environ 550:231-240.

Canas AI, Camarero S. 2010. Laccase and their natural mediators: Biotechnological tools for sustainable eco-friendly processes. Biotechnol Adv 28:694-705.

Curtis CF, Lines JD. 2000. Should DDT be banned by International treaty?. Parasitol Today 16:119-121.

Das S. 2014. Microbial Biodegradation and Bioremediation. First ed. Elsevier: London.

Da Silva CJ et al. 2010a. Effect of the herbicides bentazon and diuron on the production of ligninolytic enzymes by Ganoderma lucidum. Int Biodeterior 64:156-161.

Da Silva CJ et al. 2010b. Comparative removal of bentazon by Ganoderma lucidum in liquid and solid state cultures. Curr Microbiol 60:350-355.

D’Souza TM et al. 1999. Lignin-modifying enzymes of the white-rot basidiomycete Ganoderma lucidum. Appl Environ Microbiol 65:5307-5313.

Foght J et al. 2001. Bioremediation of DDT-contaminated soils: a review. Bioremediat J. 5:225-246.

Hai FI et al. 2012. Pesticides removal by a mixed culture of bacteria and white-rot fungi. J Taiwan Inst Chem Eng 43:458-461.

Jeon J et al. 2008. Synergistic effect of laccase mediators on penthachlorophenol removal by Ganoderma lucidum laccase. Appl Microbiol Biotechnol 81:783-790.
Kammanavalli CM, Ninnekar HZ. 2004. Biodegradation of DDT by a Pseudomonas species. Curr Microbiol 48:1013.

Kumar M, Philip L. 2006. Enrichment and isolation of a mixed bacterial culture for complete miniralization of endosulfan. J Environ Sci and Health B 1234:81-96.

Liu D et al. 2012. The genome of Ganoderma lucidum provide insight into triterpense biosynthesis and wood degradation. PLoS One 7:36146.

Miller RM, Zhang Y. 1994. Effect of a Pseudomonas rhamnolipid biosurfactant on cell hydrophobicity and biodegradation of Octadecane. Appl Environ Microbiol 60:2101-2106.

Moussa TAA et al. 2014. Production and characterization of di-rhamnolipid produced by Pseudomonas aeruginosa TMN. Brazillian J Chemi Eng 31:867-860.

Punnapayak H et al. 2009. Polycyclic aromatic hydrocarbons (PAHs) degradation by laccase from a tropical white rot fungus Ganoderma lucidum. African J Biotechnol 8:5879-5900.

Purnomo AS et al. 2017. Evaluation of the synergistic effect of mixed cultures of white-rot fungus Pleurotos ostreatus and biosurfactant-producing bacteria on DDT biodegradation. J Microbiol Biotechnol 27:13061315.

Purnomo AS et al. 2008. Degradation of 1,1,1-trichloro-2,2bis (4-chlorophenyl) ethane (DDT) by brown rot fungi. J Biosci Bioeng 105:614-621.

Rubilar O et al. 2013. Are white-rot fungi a real biotechnological option for the improvement of environment health?. Crit Rev Biotechnol 8551:1-8.

Sariwati A et al. 2017. Abilities of co-cultures of brown-rot fungus Fomitopsis pinicola and bacillus subtilis on biodegradation of DDT. Curr Microbiol 74:1068-1075.

Sariwati A, Purnomo AS. 2018. The effect of Pseudomonas aeruginosa addition by brown-rot fungus Fomitopsis pinicola. Indones J Chem 18:75-81.

Ting WTE et al. 2011. Biodegradation of phenanthrene and pyrene by Ganoderma lucidum. Int Biodeterior Biodegrad 65:238-242.

Turusov V et al. 2002. Dichlorodiphenyltrichloroethane (DDT): Ubiquity, Persistence, and Risks. Environ Health Perspect 110:125-128.

Zhao YC et al. 2010. Fundamental study of degradation of dichlorodiphenyltrichloroethane in soil by laccase from white rot fungi. Int J Environ Sci Technol 7:359366. 